\title{
Chord-Interval, Direct-Familiarization, Musical Instrument Digital Interface, Circle of Fifths, and Functions as Basic Piano Accompaniment Transposition Techniques
}

\author{
Almighty C. Tabuena \\ almighty.tabuena@gmail.com; tabuena.ac@pnu.edu.ph; almighty.tabuena@esps.edu.ph \\ Graduate Student, College of Graduate Studies and Teacher Education Research, Philippine Normal University, Manila, Philippines; \\ Senior High School Faculty Member, High School Department, Espiritu Santo Parochial School of Manila, Inc., Manila, Philippines
}

\begin{abstract}
This research article aimed to examine and describe different research-based practical and transmedia transposition techniques as basic transposition methods for piano accompaniment. The need for transposition in music, particularly in piano accompaniment, whether in a single line melody, a scale, or an entire composition, is to provide the constituents in the music industry like musicians, pianists, singers, composers, and arrangers with ease and comfortable playing or singing performance using both traditional and/or technological (transmedia) transposition techniques. The most practical way of reading a music sheet is the combination of a lead sheet which composed of the melody and its respective chord/s for each measure or within the measures. Sometimes, song compositions such as folk songs and other traditional songs are just written in a single staff with its defined lyrics. The concern in this matter is the chord that would be used in accompanying the song. In making an accompaniment for this type of music, we could use the three basic types of harmonic progressions in a downward or upward manner by seconds, thirds, and fourths. After learning the basics of chord progressions, the five identified research-based techniques might be used for the process of transposition by church clavinovist and piano enthusiast namely Chord and Interval Transposition Technique, Familiarization and Direct Transposition Technique, Musical Instrument Digital Interface Transposition Technique, Circle of Fifths Transposition Technique, and Functions Transposition Technique.
\end{abstract}

Keywords: methods; piano; piano accompaniment; techniques; transposition

\section{Introduction}

The need for transposition in music whether in a single line melody, a scale, or an entire composition is to provide the constituents in the music industry (musicians, pianists, singers, composers, arrangers, and so on) with ease and comfortable performance whether in playing or singing, traditionally or technologically transposed (transmedia). Most of the time, playing and singing might be performed together, so there would be a high chance of collaboration and management in order to attain the needs of both concerns in terms of musicality or of a certain product. Transposition according to the written quote of Musikalisches Lexicon, Heinrich Christoph Koch, from Analyzing Atonal Music by Schuijer (2008), is the shifting of a melody, a harmonic progression or an entire musical piece to another key, while maintaining the same tone structure, that is, the same succession of whole tones and semitones and remaining melodic intervals. For example, one might transpose an entire piece of music into another key. Similarly, one might transpose a tone row or a notin-ordered collection of pitches such as a chord so that it begins on another pitch. Although transpositions are usually written out, musicians are occasionally asked to transpose music "at sight", that is, to read the music in 
one key while playing in another. Before we proceed to the methods of transposition, let us identify first the art of making a music accompaniment through analysis and understanding of chord progressions.

\section{Understanding the Chord Progression for Piano Accompaniment}

The most practical way of reading a music sheet is the combination of a lead sheet - the melody, and its respective chord/s for each measure or within the measures. Sometimes, song compositions such as folk songs and other traditional songs are just written in a single staff with its defined lyrics. The concern in this matter is the chord that would be used in accompanying the song. For example, the song below (Figure 1) entitled "Sitsiritsit," is in the strophic form, where the verses are all in the same tune.
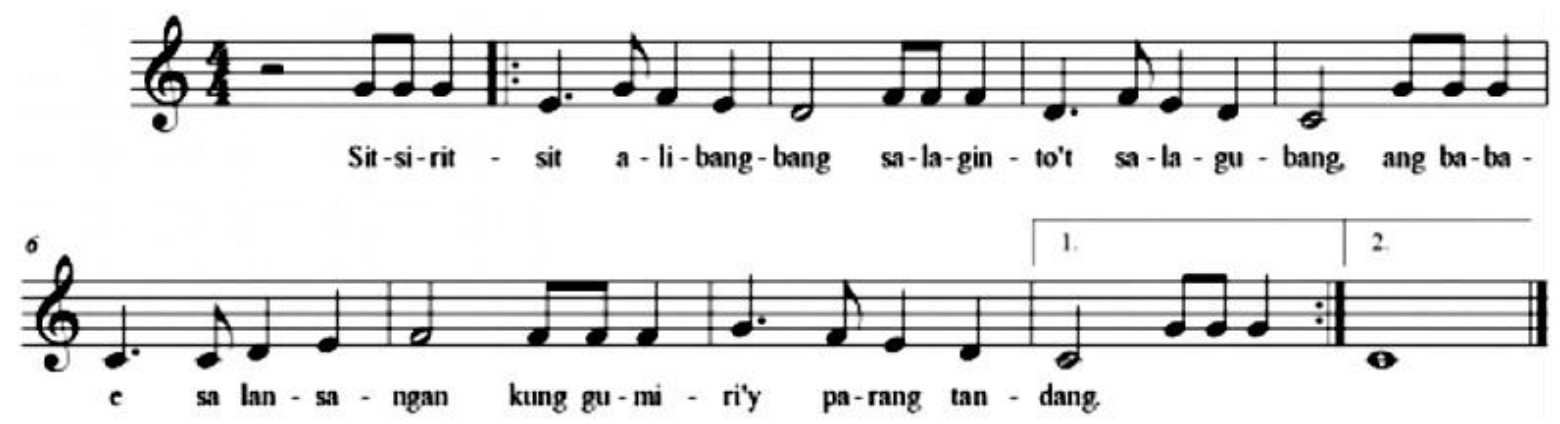

Fig. 1. Sample Music Sheet

In this example (Figure 1), making an accompaniment for this type of music could use the basic three types of harmonic progressions in a downward or upward manner by seconds, thirds, and fourths - for this music, we will use the harmonic progression by fourth. Harmonic progression (Isaacs \& Martin, 1990) is the relationship between successive chords from the root (tonic chord).

\subsection{Music Notation Analysis}

The composition (Sitsiritsit) is in the key of $\mathrm{C}$ major, in a quadruple meter and most of the melodies are in step-wise ascending and descending pitch direction (Tabuena, 2018a). The three family chords of $\mathrm{C}$ Major are the following (Cazaubon, 2018): (a) C Chord, composed of the notes do, mi and sol; (b) F Chord, composed of the notes fa, la, and do; and (c) G Chord, composed of the notes sol, ti and re, or an additional fa for a G7. Moreover, we might use the other chords such as the following: (a) B diminished chord - ti, re, fa; (b) E minor chord - mi, sol, ti; (c) A minor chord - la, do, mi; and (d) D minor chord - re, fa, sol. The accompaniment will start at the second measure with the tonic chord, the $\mathrm{C}$ Major Chord. In the third measure, if you observed, it composed of the notes re and fa, which might be applicable for D minor chord, G7 chord, or B diminished chord - yet, using the harmonic progression by fourths (downward or upward), the G7 chord is the most suitable for the next chord up to the fourth measure.

In the fifth measure, it is composed of the notes do and sol (lyrics: bang, ang baba-) which only visible in a triad of the $\mathrm{C}$ chord - the $\mathrm{C}$ chord will continue up to the sixth measure in which the pitch direction moves upward going to the note fa, so the $\mathrm{C}$ chord will stop in the sixth measure going to another chord. The seventh measure is just composed of the note fa which visible to the F chord, B diminished, and D minor chord. Using again the harmonic progression by fourths, the F chord is the most suitable. 
Take note, we only used the harmonic progression by fourths to limit the extent of many possibilities in making an accompaniment for piano and to understand more the basics of the transposition method (the focus of the article). In the music world, all of the music theory could be used as much as the artist or the musician is concerned. The last two measures (seventh and eighth measure) of the composition which involved a harmonic progression is generally called a cadence. If we used the harmonic progression by fourths - upward, it would be a plagal cadence $-\mathrm{F}$ chord for the eighth measure and $\mathrm{C}$ chord for the last measure; but if we used the harmonic progression by fourths - downward, it would be a perfect cadence - G or G7 chord for the eighth measure and $\mathrm{C}$ chord for the last measure.

In this piece, we will use the perfect cadence. Thus, if we used the drone style of accompaniment which at times the chord/s or the accompaniment lasts for a measure - a whole note or more than of its value (Tabuena, 2020; Tabuena, 2018c), the music sheet below would be the result:

C

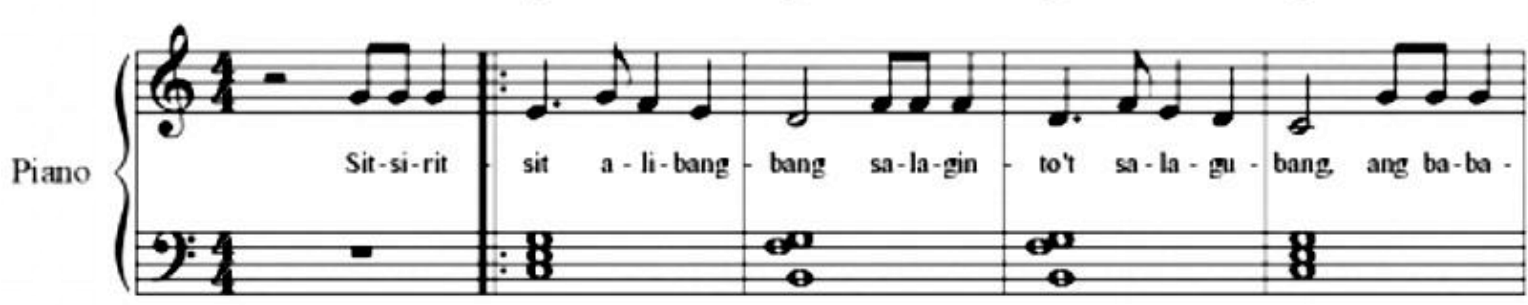

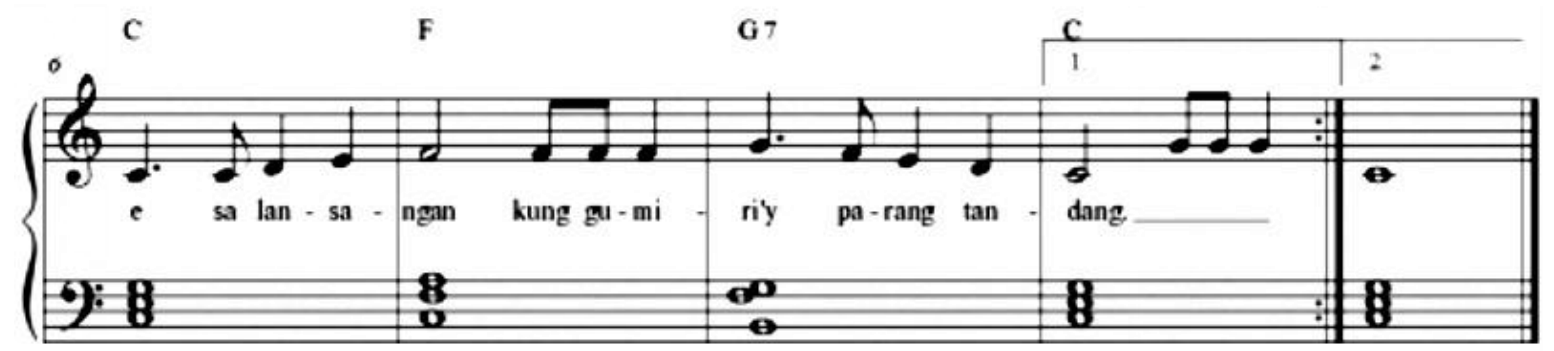

Fig. 2. Sample Music Sheet in Drone Accompaniment

After learning the basics of chord progressions, let us begin with the basic transposition methods for piano accompaniment using the song Sitsiritsit. The five techniques (Tabuena, 2018b) might be used for the process of transposition by church clavinovist and piano enthusiast: Chord and Interval Transposition Technique, Familiarization and Direct Transposition Technique, Musical Instrument Digital Interface Transposition Technique, Circle of Fifths Transposition Technique, and Functions Transposition Technique.

\section{Practical and Transmedia Transposition Methods}

\subsection{Chord and Interval Transposition Technique}

Basically, this method is an easy approach for a piano sheet music which has two components: the lead sheet or the melody, and the written chord/s encoded above the lead sheet as shown below: 
C

G7

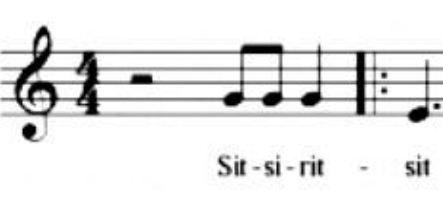

F

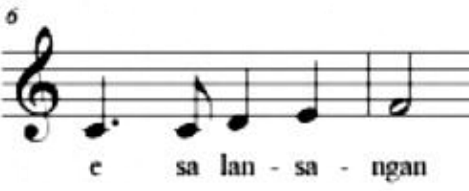

G7
C

Fig. 3. Sample Music Sheet with Written Chords

Before we transpose the music, we should know all the key signatures in the chord alphabet from A to $G$ including the chromatics. First, identify the movement of the notes of the melody (in the lead sheet), and second, acknowledge the chord.

In identifying the movement of the notes of the melody, we consider the finger positions and numbers assigned to each finger in both left and right hands, yet in this composition, we only use the right hand for the melody. There are only five notes in the composition, consists of the notes do, re, mi, fa, and sol which are played by fingers: thumb, index, middle, ring, and little (or pinky) respectively. If we move the fingers upward on piano a whole step (whole tone), the notes will be re, mi, fa, sol, la respectively, and if we move the fingers downward on piano a three half steps (semitone), we have the notes la, ti, do, re and mi respectively. Afterward, we are going to assign a number for each note in accordance with the finger numbers as $1,2,3,4$, and 5 respectively.

In acknowledging the chords, the question is - in what key will the composition go to. For example, from $\mathrm{C}$ major going to $\mathrm{F}$ major, or E-flat major, or $\mathrm{G}$ major; in this particular matter, we will transpose the composition to $\mathrm{G}$ major - from $\mathrm{C}$ note (do) it will be a $\mathrm{G}$ note (sol) now, and others are shown below:

\begin{tabular}{|c|c|}
\hline From C Major Key & To G Major Key \\
\hline re & la \\
\hline $\mathrm{mi}$ & $\mathrm{ti}$ \\
\hline $\mathrm{fa}$ & $\mathrm{do}$ \\
\hline $\mathrm{sol}$ & $\mathrm{re}$ \\
\hline $\mathrm{la}$ & $\mathrm{mi}$ \\
\hline $\mathrm{ti}$ & fa-sharp (fi) \\
\hline
\end{tabular}

Fig. 4. Chord and Note Transposition Guide from C to G Major Key

\begin{tabular}{|c|c|}
\hline From C Major Chord & To G Major Chord \\
\hline D minor & A minor \\
\hline E minor & B minor \\
\hline F major & C major \\
\hline G major & D major \\
\hline A minor & E minor \\
\hline B diminished & F-sharp diminished \\
\hline
\end{tabular}

Fig. 5. Chord and Note Transposition Guide from C to G Major Chord 
Thus, the composition will be played in G major key while reading it in C major key by the manner of understanding the theory involved and by the memorization process.

\subsubsection{The Note Transposition Technique}

Another way involved in Chord and Interval Transposition Technique is the Note Transposition Technique where each note in the composition is transposed by the manner of writing it. For example, when transposing from $\mathrm{C}$ major key to $\mathrm{F}$ major key, each note has to be five semitones higher: note la (A) becomes re (D), note sol (G) becomes do (C), and so on. The piece now would be written as shown below (Figure 6), from the previous notation (Figure 3).

G

D7

D7

G

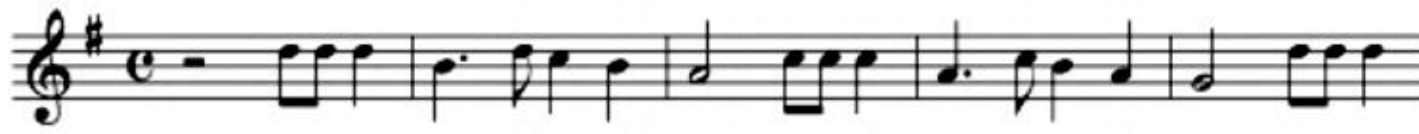

G

C

D7

G

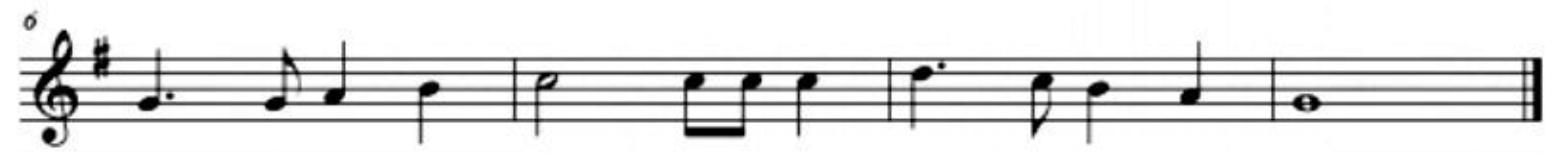

Fig. 6. Sample Note Transposition Technique

\subsection{Familiarization and Direct Transposition Technique}

The other method of transposition is a basic one if you know all the key signatures - their respective scales, chords, intervals - and the entire music composition through playing the piano piece itself, it is called the Familiarization and Direct Transposition Method. When we say familiarization, it is the process of informing, instructing, or giving knowledge about something, in music it is the way for pianists to acquaint themselves in a certain composition that leads toward memorization and able to remember the flow of the entire musical piece. Gradually, in this method, you are now capable to play the piece without the music sheet. After that preliminary process, you would be able to transpose directly the entire piece in the chosen key with ease or at least some of the musical aspects in the given piece such as the key signature, the melody, the chord involved, the harmonic progression, the pattern, and so on. from the notation below to the different (desired) key [signature] (Figure 3).

\subsection{Musical Instrument Digital Interface Transposition Technique}

MIDI, short for Musical Instrument Digital Interface is a technical standard that describes a communications protocol, digital interface, and electrical connectors that connect a wide variety of electronic musical instruments, computers, and related music and audio devices (Swift, 1997). Using this kind of musical process, MIDI is now the responsible for transposition method resulting from a very definite music sheet/s in a different kind or chosen key signature/s. The following is the process of transposing a musical composition using the Musical Instrument Digital Interface, and with the help of music software called Finale, which used by composers, songwriters, and arrangers for creating sheet music (Nicholl \& Grudzinski, 2007): 


\subsubsection{First Step: Running the Software}

Run the software (Finale or other music software such as Sibelius, Crescendo, Finale Notepad), and wait to launch the window; in this example, we used the Finale PrintMusic 2014 (MakeMusic, Inc., 2018) as shown in Figure 7. Then click the "Setup Wizard". Select an ensemble based on your choice, but in this process basically, click the "Create New Ensemble" and then click the "Next" button as shown below (Figure 8). Afterward, select "Keyboards" in the first column and "Piano" in the second column, and proceed to "Add," then click the next button (Figure 9).

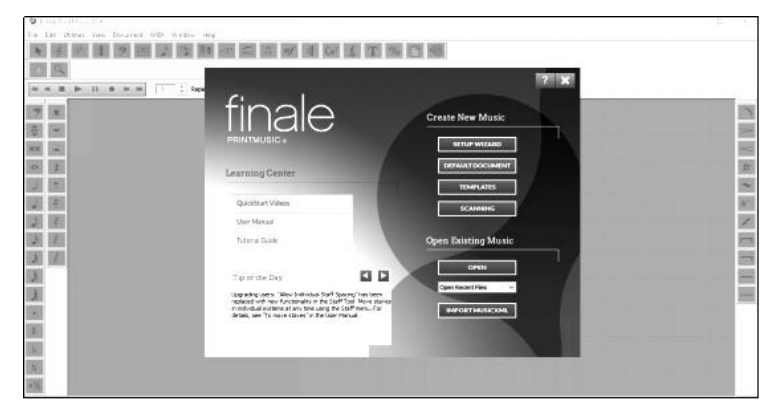

Fig. 7. Finale PrintMusic 2014 Setup Wizard

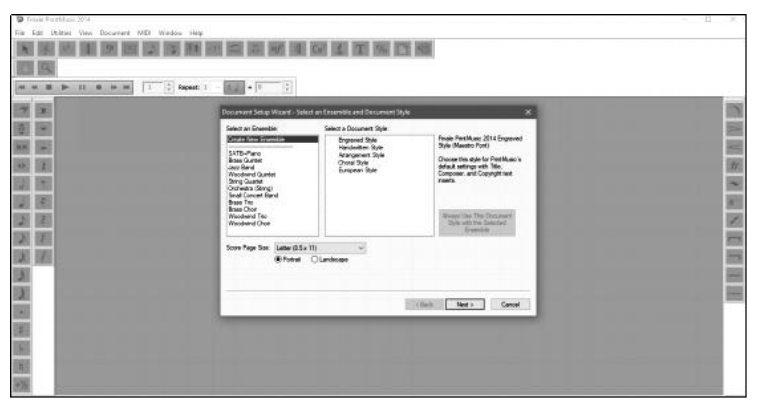

Fig. 8. Select an Ensemble Prompt Dialog Box

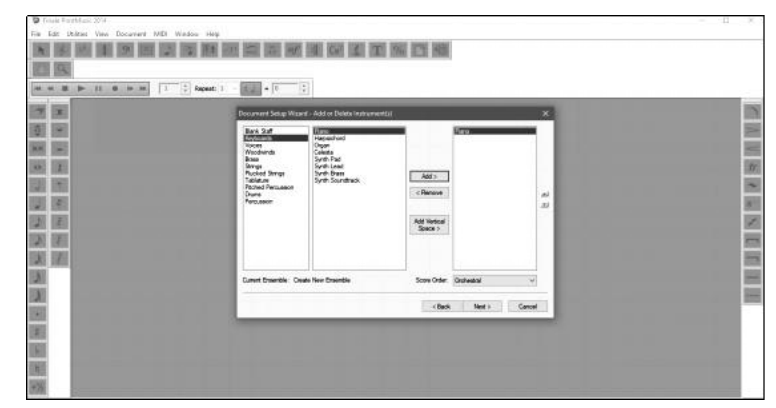

Fig. 9. Select an Ensemble Prompt Dialog Box 


\subsubsection{Second Step: Filling-up the Setup Wizard}

Complete the "Document Setup Wizard - Score Information, and click the "Next" button. After filling up the score information, proceed to complete the score setting, then click the "Finish" button as shown below (Figure 10): Time Signature: Common Time (Four-four or 4/4 Time); Key Signature: C Major; Tempo Marking: 120; Specify Pickup Measure: Quarter Note; and Number of Measures: 9. The picture in Figure 11 will be the interface after filling-up the needed information in notating a music sheet for transposition.

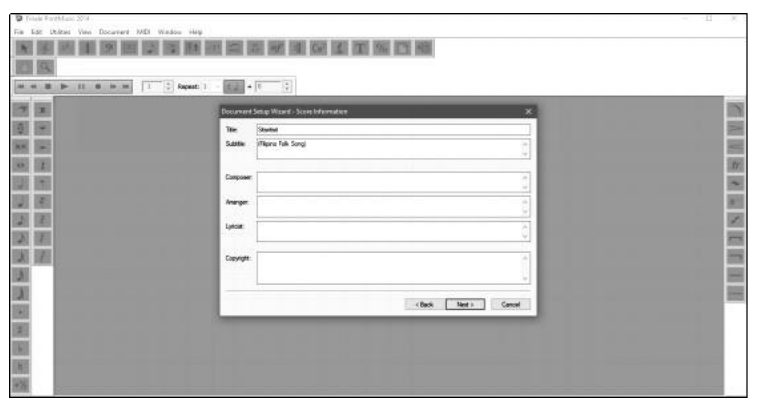

Fig. 10. Score Information Prompt Dialog Box

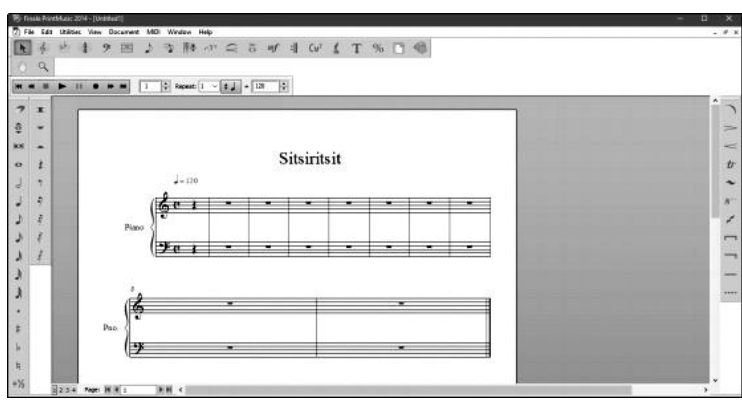

Fig. 11. Music Sheet Interface

\subsubsection{Third Step: Notating the Piece}

Notate the music piece you would like to transpose in the interface using the commands that are surrounded by the music staff. In the music sheet, you could write the lyrics of the song and indicate the appropriate chords in each measure above the staff.

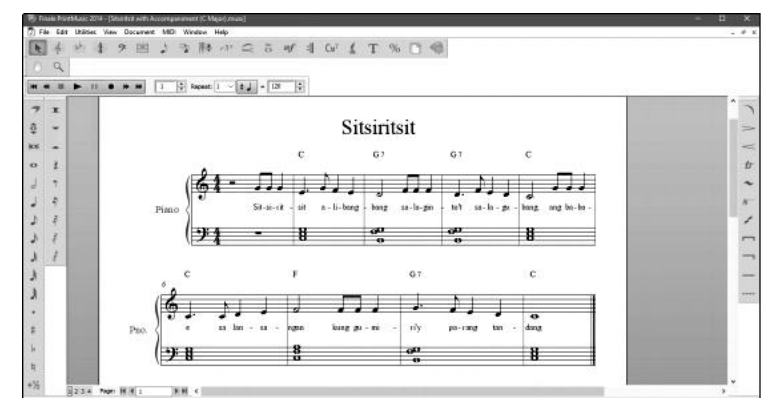

Fig. 12. Notating the Piece 


\subsubsection{Fourth Step: Transposing the Music Piece}

In the interface, select the "Selection Tool," and the "Key Signature Tool" located above the interface as shown in Figure 13 (selection tool encircled with dark color, key signature tool encircled with light color):

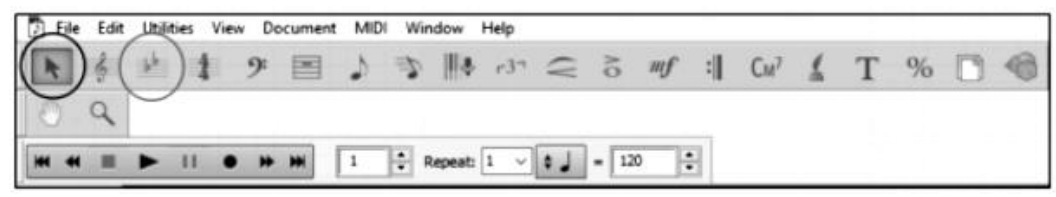

Fig. 13. Selection Tool and Key Signature Tool

Then double-click the first measure of the staff to insert a key change (in transposing the music). A dialog box will appear indicating "Key Signature." Select the key you want to transpose - example in G Major, and complete the other information, after that click the "OK" button as shown in Figure 14: Measure Region: Measure [1] through end of piece; Transposition Options: Transpose notes [Up].

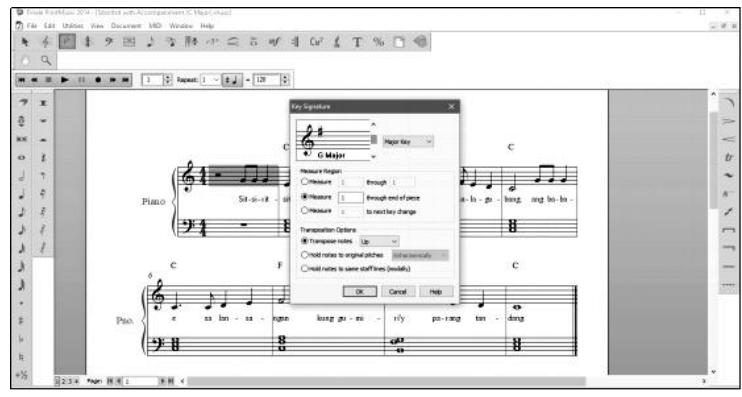

Fig. 14. Signature Dialog Box

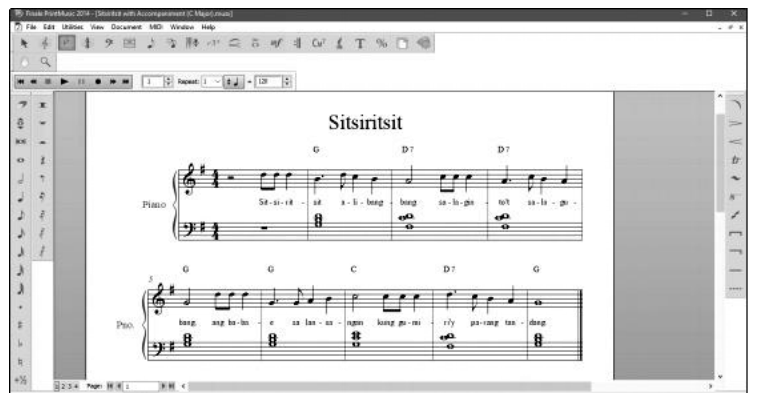

Fig. 15. Transposed Music Piece

After clicking the "OK" button, the piece would be transposed in G Major automatically, and you could now play the entire piece with ease as shown in Figure 15. If you want to have a hard-copy of the music sheet, you could save the file by exporting it in PDF file format and print it. It is very important to understand the key system in order to be able to transpose. This is why it is so useful to practice scales. Of course, it takes practice to be able to transpose on sight, so musicians new to transposition might want to pencil in note names on a working copy of their sheet music. Modern technology can help. Music writing software such as Sibelius or Finale can be used to write out a new version of the music in another key (Making Music Magazine, 2015). 


\subsection{Circle of Fifths Transposition Technique}

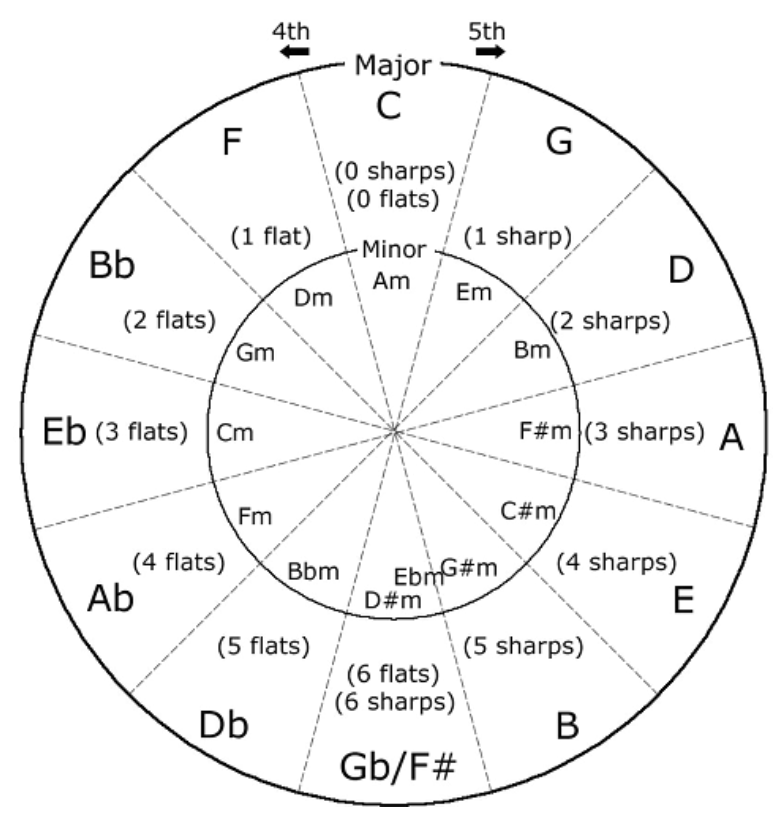

Fig. 16. Circle of Fifths

Circle of Fifths according to Winold (1966), has the tonics of all major and minor keys arranged according to the interval of the perfect fifth. This technique determined whether one tonality is related or distant from another. In addition, music theory and other concepts could help to locate the chords on the circle. Take a look at the sample circle of fifths, let's say you were playing a song in the key of G, and someone asked to lower it by one whole step, going to F (key). From G, there are two half-steps going to F ( $\mathrm{G}$ to $\mathrm{Gb}$, and $\mathrm{Gb}$ to $\mathrm{F}$ ), therefore, if the note is $\mathrm{C}$, go two steps counterclockwise (from $\mathrm{C}$ ) then $\mathrm{Bb}$ is its transposed note. The major chords are no longer $\mathrm{G}, \mathrm{C}$, and $\mathrm{D}$, but are $\mathrm{F}, \mathrm{Bb}$, and $\mathrm{C}$. The minor chords are no longer Am, Bm, and Em, they are now Gm, Am, and Dm.

\subsection{Functions Transposition Technique}

Functions in music is the term used to denote the relationship of a chord or a scale degree to a tonal center (Piston, 1950). This technique combined the other techniques in transposition such as the chord and interval transposition technique, familiarization and direct transposition technique, and the circle of fifths transposition technique, with the concept of chord progressions. In transposing the chord progressions using this technique, change the letter name of the chord to functions such as the following (in this case, we will use the C Major Scale):

Table 1. Functions and Scale in C Major Scale

\begin{tabular}{|c|c|c|c|c|c|c|c|}
\hline Functions & I & ii & iii & IV & V & vi & vii $^{\circ}$ \\
\hline C Major Scale & $\mathrm{C}$ & Dm & Em & $\mathrm{F}$ & $\mathrm{G}$ & A & $\mathrm{B}^{\circ}$ \\
\hline
\end{tabular}


The function symbols in each chord represent the general chord(s) you will be playing. In this process, you will just memorize the sequence of the chords as well as the functions. The symbol ${ }^{0}$ means diminished, $\mathrm{B}^{0}$ as B diminished. For example, from D Major Key to A Major Key:

Table 2. Functions Transposition from D Major Key to A Major Key

\begin{tabular}{lccccccc}
\hline Functions & I & ii & iii & IV & V & vi \\
\hline D Major Scale & D & Em & F\#m & G & A & Bm \\
A Major Scale & A & Bm & C\#m & D & E & F\#m \\
\hline
\end{tabular}

Other chords as follows:

Table 3. Functions Transposition in Other Keys

\begin{tabular}{|c|c|c|c|c|c|c|c|}
\hline Functions & $\mathrm{I}$ & ii & iii & IV & $\mathrm{V}$ & vi & vii $^{\circ}$ \\
\hline E Major & $\mathrm{E}$ & $\mathrm{F} \# \mathrm{~m}$ & $\mathrm{G} \# \mathrm{~m}$ & A & B & $\mathrm{CHm}$ & $\mathrm{D} \#^{\circ}$ \\
\hline F Major & $\mathrm{F}$ & $\mathrm{Gm}$ & Am & $\mathrm{Bb}$ & $\mathrm{C}$ & $\mathrm{Dm}$ & $\mathrm{E}^{\mathrm{o}}$ \\
\hline G Major & $\mathrm{G}$ & $\mathrm{Am}$ & $\mathrm{Bm}$ & $\mathrm{C}$ & $\mathrm{D}$ & Em & $\mathrm{F} \#^{\circ}$ \\
\hline B Major & B & $\mathrm{CHm}$ & $\mathrm{D} \# \mathrm{~m}$ & $\mathrm{E}$ & $\mathrm{F} \#$ & $\mathrm{G} \# \mathrm{~m}$ & $\mathrm{~A} \#^{\circ}$ \\
\hline Bb Major & $\mathrm{Bb}$ & $\mathrm{Cm}$ & $\mathrm{Dm}$ & $\mathrm{Eb}$ & $\mathrm{F}$ & $\mathrm{Gm}$ & $\mathrm{A}^{\mathrm{o}}$ \\
\hline Eb Major & $\mathrm{Eb}$ & $\mathrm{Fm}$ & $\mathrm{Gm}$ & $\mathrm{Ab}$ & $\mathrm{Bb}$ & $\mathrm{Cm}$ & $\mathrm{D}^{\circ}$ \\
\hline Ab Major & $\mathrm{Ab}$ & $\mathrm{Bbm}$ & $\mathrm{Cm}$ & $\mathrm{Db}$ & $\mathrm{Eb}$ & $\mathrm{Fm}$ & $\mathrm{G}^{\mathrm{o}}$ \\
\hline
\end{tabular}

\section{Conclusion}

The most practical way of reading a music sheet is the combination of a lead sheet which composed of the melody and its respective chord/s for each measure or within the measures. Sometimes, song compositions such as folk songs and other traditional songs are just written in a single staff with its defined lyrics. The concern in this matter is the chord that would be used in accompanying the song.

In making an accompaniment for this type of music, we could use the three basic types of harmonic progressions in a downward or upward manner by seconds, thirds, and fourths. After learning the basics of chord progressions, the five identified research-based techniques might be used for the process of transposition by church clavinovist and piano enthusiast namely Chord and Interval Transposition Technique, Familiarization and Direct Transposition Technique, Musical Instrument Digital Interface Transposition Technique, Circle of Fifths Transposition Technique, and Functions Transposition Technique.

\section{References}

Cazaubon, M. (2018). Basic piano chords (easy piano chords). Piano Keyboard Guide. WordPress. https://www.piano-keyboardguide.com/basic-piano-chords.html

Isaacs, A. \& Martin, E. (1990). The hamlyn illustrated encyclopedia of music. London: The Hamlyn Publishing Group Limited.

MakeMusic, Inc. (2018). Printmusic user manual home. Finale PrintMusic 2014. Boulder, CO: MakeMusic, Inc. https://usermanuals.finalemusic.com/PrintMusic2014Win/PrintMusic.htm

Nicholl, M. \& Grudzinski, R. (2007). Music notation: Preparing scores and parts, ed. Jonathan Feist. Boston: Berklee Press.

Piston, W. (1950). Tonal functions of the scale degrees. Harmony. London, Gollancz. 
Schuijer, M. (2008). Analyzing atonal music: Pitch-class set theory and its contexts. Rochester, NY; Woodbridge, Suffolk: Boydell \& Brewer. https://www.jstor.org/stable/10.7722/j.ctt14brsj5

Swift, A. (1997). A brief introduction to MIDI. SURPRISE: Imperial College of Science Technology and Medicine.

Tabuena, A. C. (2020). Functional approach as a beginning method for teaching and learning piano accompaniment in music. International Journal of Trend in Scientific Research and Development, 5(1), 51-54. https://doi.org/10.5281/zenodo.4276589

Tabuena, A. C. (2018a, July 10). Musical analysis of music composition. Music Classroom Guide: Asian and Contemporary Music. https://doi.org/10.13140/RG.2.2.19596.74889

Tabuena, A. C. (2018b). Practical-transmedia transposition techniques for piano accompaniment: A preliminary analysis and understanding of chord progressions. Kindle Direct Publishing. https://www.researchgate.net/publication/336838984_PracticalTransmedia_Transposition_Techniques_for_Piano_Accompaniment_A_Preliminary_Analysis_and_Understanding_of_Chord_Prog ressions

Tabuena, A. C. (2018c). Functional approach in piano accompaniment: A beginning method and guide for piano enthusiast in accompanying music. Kindle Pirect https://www.researchgate.net/publication/336838661_Functional_Approach_in_Piano_Accompaniment_A_Beginning_Method_and _Guide_for_Piano_Enthusiast_in_Accompanying_Music

Winold, A. (1966). Elements of musical understanding. Englewood Cliffs, New Jersey: Prentice-Hall, Inc. 